\title{
Snakebite neglect rampant in Africa
}

$\mathrm{N}$

o part of the world is free of snakebites. It is a particular problem, though, in parts of Africa, which is home to more than 400 snake species, of which about 30 venomous species, belonging to four families - atractaspididae, colubridae, elapidae and viperidae - are known to have caused human deaths, according to the World Health Organization (WHO).

Snakes are, of course, most ubiquitous in tropical areas and as agricultural development encroaches on such territory, snakebites become more common, though farmers often have a love-hate relationship with the slithering reptiles because they prey on rodents while being an occupational hazard for agricultural workers.

Africa's relationship with snakes is further compounded by the fact that snakes are used by some in witchcraft rituals and as a food source by others. "Larger snakes such as pythons and Bitis species are frequently eaten as delicacies and valuable protein supplements," and some diners become infected with the parasite, pentastomid, from consuming uncooked snake, the WHO says in its Guidelines for the Prevention and Clinical Management of Snakebite in Africa (www.afro.who .int/index.php?option=com_docman\& task=doc_download\&gid=5529).

Because medical recordkeeping is so fragmented and incomplete in Africa, the exact incidence of snakebite on the continent is unknown. But Dr. JeanPhilippe Chippaux, an epidemiologist with the Institute of Research for Development in Cotonou, Benin, says that health reporting systems alone indicate that the incidence of envenoming by snakebites in Africa is about 315000 per year, resulting in more than $7000 \mathrm{ampu}-$ tations and between 7000 and 32000 deaths. Based on household surveys, the incidence rises to 1.5 million and the number of deaths to 32000 annually, he adds. More than $95 \%$ of the snakebites occur in rural Africa, where antivenin

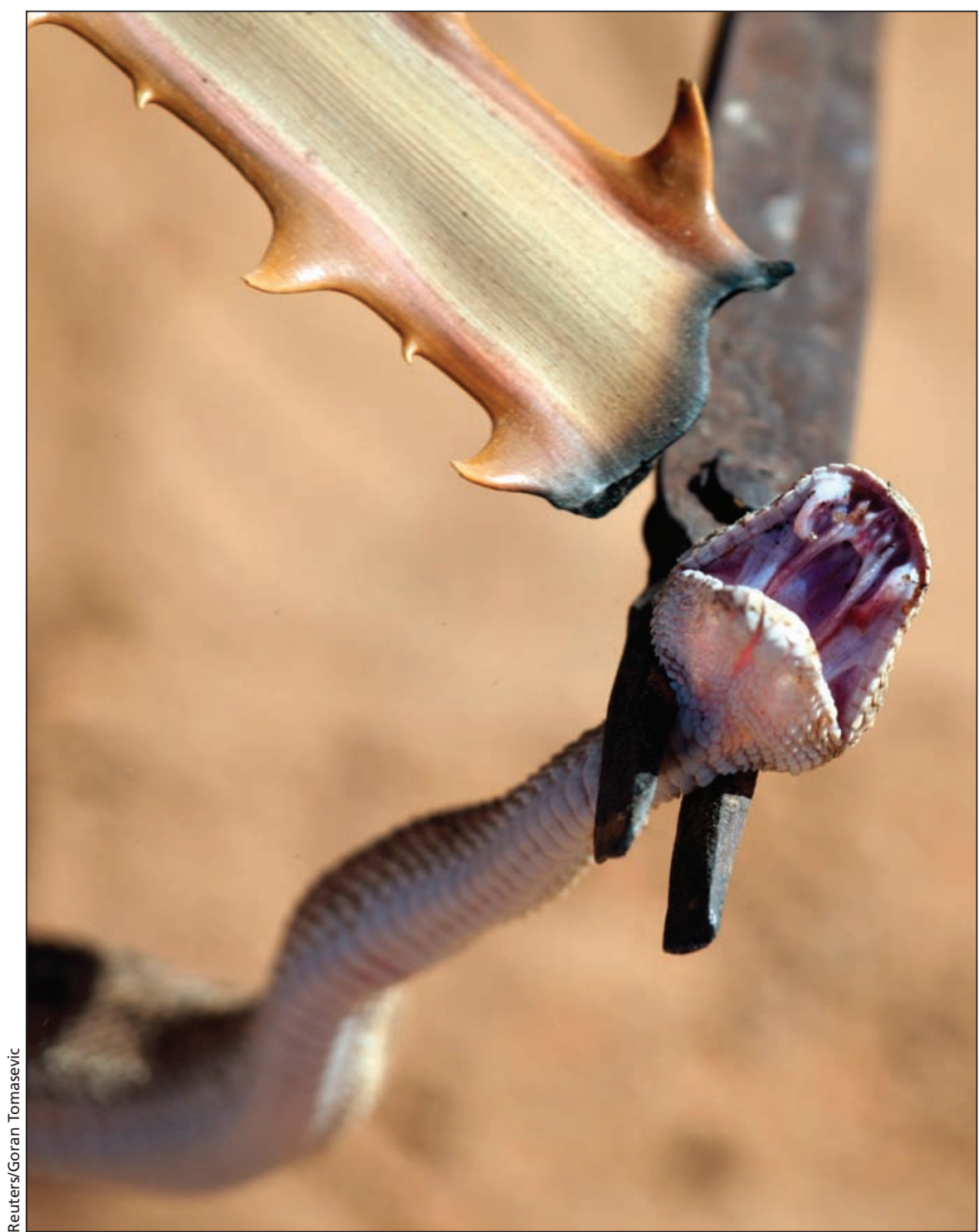

A man holds a poisonous snake with a pair of pliers in Africa.

therapy is not always available within 24 hours, as recommended.

Further compounding the snakebite problem in Africa has been the therapeutic challenge which ensued after pharmaceutical companies either stopped or scaled back production of antivenins because of low-profit margins, which prompted the WHO in 2009 to declare snakebite a neglected tropical disease.

African health authorities, meanwhile, have largely ignored the problem, either because they do not have accurate data, and thus are unaware of the incidence rates, or do not think they can do anything to solve it, Chippaux says.

More than 200 experts gathered at the 4th International Conference on Envenomations by Snakebites and Scorpion Stings in Dakar, Senegal earlier this year in hopes of building a measure of political will to address the problem. Chippaux says that recommendations which emerged included the development of a continent-wide 
snakebite notification or surveillance system to generate epidemiological data. Other recommendations included calls for the provision of more training of health professionals in handling snakebite and a pitch for funding from multiple stakeholders to purchase antivenins for the continent. The experts also established an African network to study and manage snakebite.

Earlier efforts to establish some manner of snakebite program included the creation of the Global Snakebite Initiative in 2008. But according to its website, the initiative is still in the process of developing a "workplan of projects" and David Williams, chief executive officer of the nonprofit organization, writes in an email that the initiative hopes to establish a public charitable fund to finance the purchase of antivenins, train doctors and health workers, craft preventive educational materials and provide rehabilitation services. Williams would like to see a situation in which no victims of snakebites must pay for therapy.

Chippaux and Dr. Abubakar Saidu Ballah, chief medical officer for a snakebite treatment centre in Nigeria, say there's a particular need for African governments to make antivenin available in rural areas, where "traditional" healers are compounding the plight of those bitten by snakes.

"In Senegal, traditional healers have virtually taken over snakebite management in rural communities, and they have been killing victims with concoctions that don't work," Ballah says, adding that without trained staff and antivenin, it is difficult to persuade rural dwellers to stop patronizing traditional healers.

For those bitten and improperly treated, particularly subsistence farmers, the consequences can include death or loss of livelihood, says Dr. Robert A. Harrison, head of the Alistair Reid Venom Research Unit of the Liverpool School of Tropical Medicine, United Kingdom. Snakebite can cause "terrible physical disability and produces longterm psychological trauma that has been found to be second only to the psychological effect of civil war."

Among the few countries with designated snakebite treatment facilities is Nigeria, which has a 24-bed centre in the northern state of Gombe. "If you see [snakebite] patients on admission, it is horrible," says Ballah, who's treated more than 17000 snakebite victims since 1999. "You find some [pregnant] women losing their fetus due to toxic effects of the venoms. People losing their limbs, their fingers, their eyes."

In most countries, the shortage of antivenin is acute, says Chippaux. Africa needs more polyvalent antivenin, but only two are available and both are manufactured off the continent and are costly (US $\$ 80$ to US $\$ 160$ per vial), well out of the range of many victims.

There is only one manufacturer of antivenin, South African Vaccine Producers, located in sub-Saharan Africa and according to the firm's manufacturing director, it can only produce 15000 vials per year.

But Chippaux says Africa needs more than two million vials annually, as well as a whole lot more commitment to address the snakebite problem. "We should have better knowledge of snakebite, political will of African governments, greater involvement of relevant bodies, including the WHO, better access to antivenoms, and trained health professionals to manage snakebite in Africa." - Bernard Appiah, Accra, Ghana

CMAJ 2012. DOI:10.1503/cmaj.109-4046 